\title{
Masking by combination tones and bands
}

\author{
DAVID Y. CHUNG \\ Bioacoustics Laboratory, Eye and Ear Hospital, Pittsburgh, Pennsylvania 15213
}

\begin{abstract}
Masking of a pure tone by a cubic difference tone or band generated by two pure tones or by a pure tone and a narrow band of noise as a function of the level of the masker was measured for three subjects at three ratios of $f_{2} / f_{1}, 1.125,1.2$, and 1.3. The three maskers used were $f_{1}$ alone, $f_{1}+f_{2}$, and $f_{1}+N B N\left(60-H z\right.$ band of noise centered at $\left.f_{2}\right)$. At ratio 1.125 , the amounts of masking produced by $f_{1}$ alone and $f_{1}+$ NBN were not significantly different for all subjects. For ratios $=1.125$ and $1.2, f_{1}+f_{2}$ produced the least masking at least in two of the subjects. $f_{1}+$ NBN was the best masker at ratios 1.2 and 1.3. These results show that the masking data on cubic difference tone at very small ratios of $f_{2} / f_{1}$ are not reliable due to the masking effect contributed by $f_{1}$. For higher ratios, the combination band has to be used instead of combination tone because of the interaction between the signal and the cubic difference tone. Also the divergence of the effectiveness in masking by the three maskers gives an estimation of the levels of primaries at which the cubic difference tone is generated.
\end{abstract}

The features of the combination tones of the type $f(k)=(k+1) f_{1}-k f_{2}$, where $k$ is a small integer and $f_{1}<f_{2}$, were studied extensively by Goldstein (1967) and Goldstein and Kiang (1968), using various methods, especially concellation [also called the method of compensation (Zwicker, 1955)]. Their data convinced them that combination tones of this class are cochlear in origin and behave like stimulus tones. Their conclusion is supported by Greenwood's (1971) observations that combination tones and bands produce masking at the frequencies around them. In his experiments, Greenwood used masking stimuli that were made up of (1) two tones, $f_{1}$ and $f_{2} ;(2)$ a tone, $f_{1}$, and a narrow band of noise $50 \mathrm{~Hz}$ wide centered at $\mathrm{f}_{2}$; and (3) two narrow bands of noise centered at $f_{1}$ and $f_{2}$. With the two-tone stimulus as masker, he found dips in masking on the low-frequency slope of the masked audiogram that corresponded to the frequencies of $2 f_{1}-f_{2}, 3 f_{1}$ $2 f_{2}$, etc. He interpreted these dips in terms of the interaction or beating between the signals and the combination tones similar to those that have been shown by Egan and Hake (1950) and Wegel and Lane (1924) for signals and harmonics of pure-tone maskers. With the other two kinds of masking stimuli, however, Greenwood found bumps on shoulders rather than dips to be evident in frequency region of the combination bands.

Greenwood (1972a) also measured signal-tomasker ratios using external bands of noise as

This study was supported by Grant 07790 from the National Institute of Neurological Disease and Stroke. The author wishes to thank R. C. Bilger for his advice during all phases of this work. The present address of the author is Division of Audiology and Speech Sciences, University of British Columbia, Vancouver, B.C., Canada V6T 1W5. masker. He then estimated the combination band levels by measuring the masked thresholds of the signals at the point of maximum masking produced by the combination bands. The levels of the combination bands can be calculated from the signalto-masker ratios that were obtained previously from an external band of noise. Earlier, Greenwood (1972b) had found that the addition of a higher tone with a higher intensity than the external masking narrow band of noise did not change the masked threshold at the maximum or on the lower slope of the masked audiogram by the noise alone in any significant extent. He also found that masking patterns produced by these external noise bands (centered at the cubic difference tone, CDT) plus the tone are almost identical to those by $\mathrm{f}_{1}$ plus a narrow band of noise centered at $f_{2}$ (NBN).

This study attempts to investigate masking as a method of studying combination tone by finding: (1) the effect of $f_{1}$ on the masking of a tone with a frequency in the vicinity of the CDT, and (2) the differences between $f_{1}+f_{2}$ and $f_{1}+N B N$ as maskers of a tone at a frequency near the CDT.

\section{METHOD}

\section{Subjects}

One female and two male college students served as subjects in this study. One of them was the experimenter himself. Subjects D.C. and M.F. were experienced in hearing experiments, while J.B. was not.

\section{Stimuli}

The two-tone masker $\left(f_{1}+f_{2}\right)$ was generated by a complex waveform generator (Wolf \& Bilger, 1972). Two tones with the same amplitude and in sine phase with each other were generated and stored on a computer tape. The third masker with the narrowband noise was generated by passing a random telegraphic noise through a low-pass filter at $30 \mathrm{~Hz}$ to a multiplier. The other input 
to the multiplier was from an oscillator with frequency at $f_{2}$. The output was added to a pure tone of $f_{1}$ by an adder. The resultant was the masker, $f_{1}$ plus a narrow band of noise, $60 \mathrm{~Hz}$ wide centered at $f_{2}$. Both components had the same sound pressure level. The nonlinear distortion components at the frequencies, $2 f_{1}-f_{2}$, were at least $50 \mathrm{~dB}$ down for the two-tone masker and $55 \mathrm{~dB}$ down for the NBN masker, as measured by a HewlettPackard 3581A wave analyzer. The signal was $500 \mathrm{msec}$ in duration and had a rise-decay time of $16 \mathrm{msec}$. The signal always had a frequency of $10 \mathrm{~Hz}$ above the frequency of the CDT. The masker was on continuously during each run. All stimuli were presented monaurally.

\section{Procedure}

An adaptive procedure based on the four-interval-forced-choice paradigm was used to estimate masked and unmasked thresholds. A randomly selected interval contained the signal. The period between intervals was 300 msec. A pair of TDH-49 headphones was used for each subject. The left one was always silent. The subjects were instructed to push the button of the interval in which they detected a difference after the four intervals were presented. During each session, the same masker was used while its level was varied from 10 to $80 \mathrm{~dB} \mathrm{SPL}$ in 10-dB steps. The sequence was repeated three times with a total of 27 runs. There was a 10 -min testing period after every four runs. Each session lasted about $3 \mathrm{~h}$. None of the subjects showed any recognizable sign of fatigue at the end of each session either from the data or the appearance. After several practice trials, quiet thresholds and masked thresholds were obtained under three different masker conditions and three different $f_{2} / f_{1}$ ratios. The ratios were 1.125 $\left(f_{1}=3,200 \mathrm{~Hz}\right), 1.2\left(f_{1}=2,000 \mathrm{~Hz}\right)$, and $1.3\left(f_{1}=2,000 \mathrm{~Hz}\right)$. The nine conditions are shown in Table 1 . A different $f_{1}$ was used for the ratio 1.125 because of the limitation of the waveform generator, which could only produce certain discrete frequencies.

\section{RESULTS}

The results of the three subjects are plotted in Figures 1-3. Each figure shows the masking functions of the three maskers in a given ratio of $f_{2} / f_{1}$ for all three subjects. The ordinate is in $\mathrm{dB}$ masking and the abscissa is in $\mathrm{dB}$ SPL of the masker.

Table 2 shows the results of the analyses of variance calculated separately for each subject at each ratio of $f_{2} / f_{1}$. For the ratio $f_{2} / f_{1}=1.125$, the masker effect is significant only in subject M.F. with $f_{1}+f_{2}$ being the least effective masker. For subject D.C., the masker effect is significant to 0.1 level with $f_{1}+$

Table 1

The Nine Different Conditions of the Experiment

\begin{tabular}{|c|c|c|c|}
\hline \multirow[b]{2}{*}{ Ratios } & \multicolumn{3}{|c|}{ Maskers } \\
\hline & $\mathrm{f}_{1}$ & $f_{1}+f_{2}$ & $\mathrm{f}_{1}+\mathrm{NBN}$ \\
\hline 1.125 & $\mathrm{f}_{1}=3,200 \mathrm{~Hz}$ & $\begin{array}{l}f_{1}=3,200 \mathrm{~Hz} \\
f_{2}=3,600 \mathrm{~Hz}\end{array}$ & $\begin{array}{l}\mathrm{f}_{1}=3,200 \mathrm{~Hz} \\
60-\mathrm{Hz} \text { band centered } \\
\text { at } 3,600 \mathrm{~Hz}\end{array}$ \\
\hline 1.2 & $\mathrm{f}_{1}=2,000 \mathrm{~Hz}$ & $\begin{array}{l}f_{1}=2,000 \mathrm{~Hz} \\
f_{2}=2,400 \mathrm{~Hz}\end{array}$ & $\begin{array}{l}\mathrm{f}_{1}=2,000 \mathrm{~Hz} \\
60-\mathrm{Hz} \text { band centered } \\
\text { at } 2,400 \mathrm{~Hz}\end{array}$ \\
\hline 1.3 & $\mathrm{f}_{1}=2,000 \mathrm{~Hz}$ & $\begin{array}{l}\mathrm{f}_{1}=2,000 \mathrm{~Hz} \\
\mathrm{f}_{2}=2,600 \mathrm{~Hz}\end{array}$ & $\begin{array}{l}f_{2}=2,000 \mathrm{~Hz} \\
60-\mathrm{Hz} \text { band centered } \\
\text { at } 2,600 \mathrm{~Hz}\end{array}$ \\
\hline
\end{tabular}

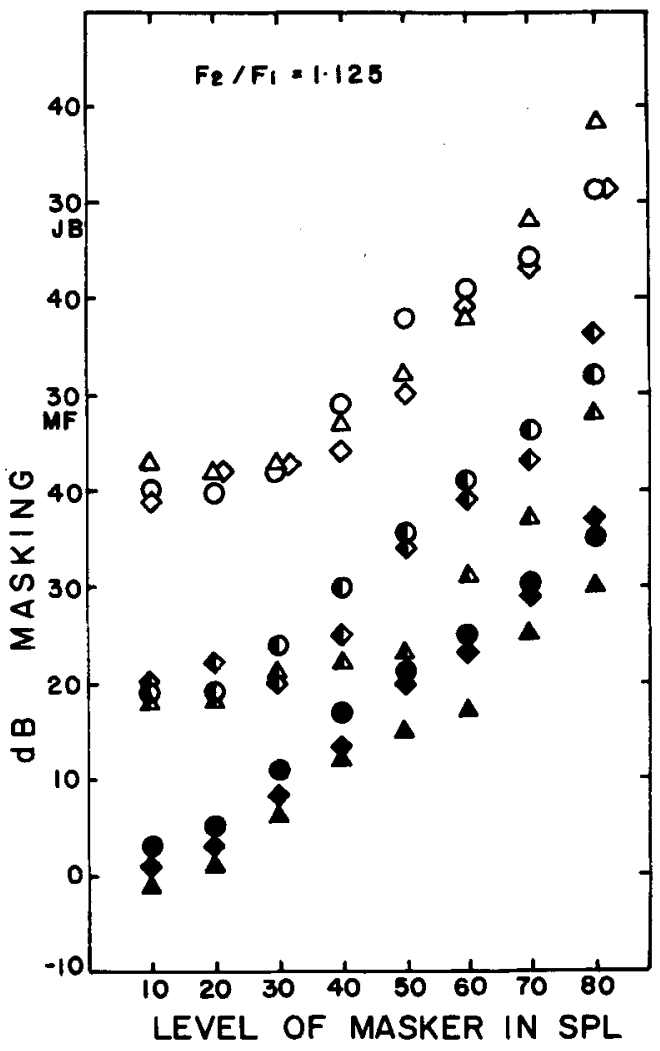

Figure 1. The masking functions of the subjects in the ratio of $f_{2} / f_{1}$ is indicated at the top of the figure, $f_{1}=3,200 \mathrm{~Hz}$. The abscissa is in dB SPL of the masker and the ordinate is in $\mathrm{dB}$ masking. Multiple ordinate scale is used. Each set of masking functions for each subject has been shifted $20 \mathrm{~dB}$ on the ordinate relative to the one below. Subject D.C., filled symbols; M.F., halffilled; and J.B., unfilled. The three maskers shown are $f_{1}$ alone (circles), $f_{1}+f_{2}$ (triangles), and $f_{1}+N B N$ (squares). The frequency of the masked tone $=2 f_{1}-f_{2}+10=2,810 \mathrm{~Hz}$.

$\mathrm{f}_{2}$ producing the least masking. For all subjects (Figure 1), $f_{1}$ and $f_{1}+N B N$ are as effective as each other in masking. At ratios 1.2 and 1.3, the masker effect is significant to .05 level for subjects D.C. and M.F., and 0.1 for subject J.B. The masker $f_{1}+f_{2}$ is still the least effective masker for the former two subjects at the ratio 1.2 (Figure 2), although it is not so definite for subject J.B. At the ratio 1.3, however, the masker $f_{1}$ alone remains the least effective masker at higher masker levels (Figure 3).

The amount of masking due to the effect of masker level is, as expected, significant in all subjects. Since the $f_{1}$ frequency in the ratio 1.125 is different from that in the ratios 1.2 and 1.3 , a full analysis of variance was not done. One can see, however, that the masking due to $f_{1}$ alone markedly decreases as the ratio goes up. The same is true for $f_{1}+f_{2}$, but the decrease is at a slower rate. For $f_{1}$ $+\mathrm{NBN}$, the masking at the ratio 1.125 to masking at the ratio 1.2 is not decreased (the $f_{1} s$ in the two 
Table 2

Analyses of Variance for Each Ratio of $f_{2} / f_{1}$

\begin{tabular}{|c|c|c|c|c|}
\hline \multirow[b]{2}{*}{ Subject } & \multirow[b]{2}{*}{ Source } & \multicolumn{3}{|c|}{$\mathrm{R}=$} \\
\hline & & 1.125 & 1.2 & 1.3 \\
\hline D.C. & $\begin{array}{l}\text { Masker } \\
\text { Level } \\
\text { Masker by Level }\end{array}$ & $\begin{array}{l}\mathrm{N}^{*} \\
\mathrm{Y} \\
\mathrm{Y}\end{array}$ & $\begin{array}{l}Y \\
Y \\
Y\end{array}$ & $\begin{array}{l}Y \\
Y \\
Y\end{array}$ \\
\hline M.F. & $\begin{array}{l}\text { Masker } \\
\text { Level } \\
\text { Masker by Level }\end{array}$ & $\begin{array}{l}\mathbf{Y} \\
\mathbf{Y} \\
\mathbf{Y}\end{array}$ & $\begin{array}{l}\mathrm{Y} \\
\mathrm{Y} \\
\mathrm{Y}\end{array}$ & $\begin{array}{l}\mathrm{Y} \\
\mathrm{Y} \\
\mathrm{Y}\end{array}$ \\
\hline J.B. & $\begin{array}{l}\text { Masker } \\
\text { Level } \\
\text { Masker by Level }\end{array}$ & $\begin{array}{l}\mathrm{N} \\
\mathrm{Y} \\
\mathrm{N}\end{array}$ & $\begin{array}{l}\mathrm{N}^{*} \\
\mathrm{Y} \\
\mathrm{Y}\end{array}$ & $\begin{array}{l}\mathrm{N}^{*} \\
\mathrm{Y} \\
\mathrm{Y}\end{array}$ \\
\hline
\end{tabular}

Note $-Y=$ significant, $N=$ not significant; $p<.05$, except where otherwise indicated. ${ }^{*} p<. l$.

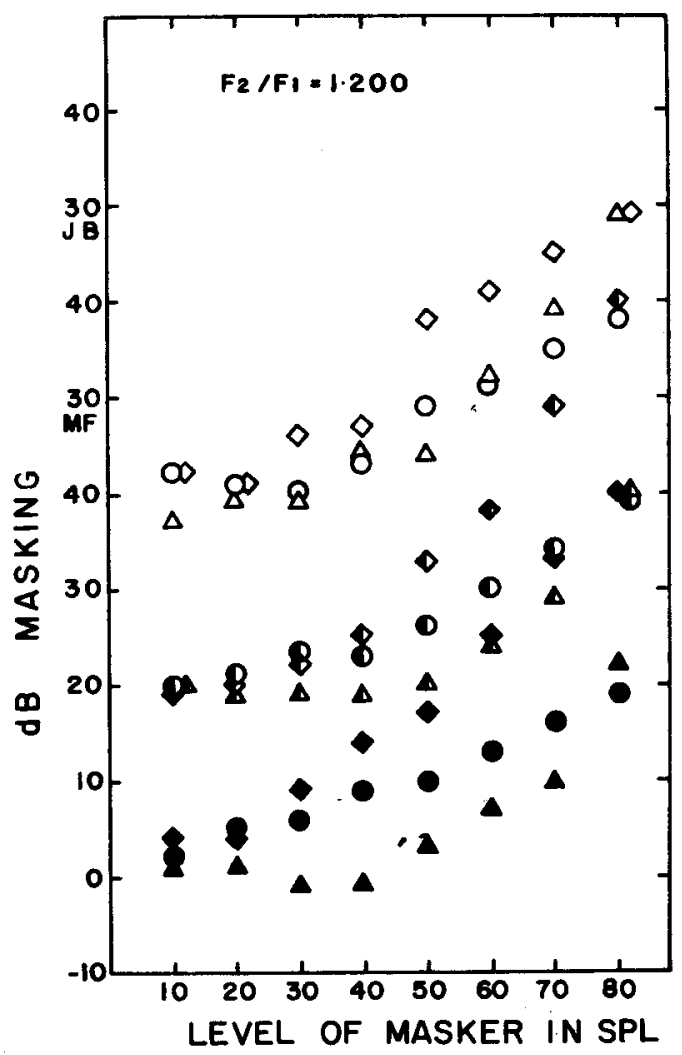

Figure 2. See caption of Figure 1, except that $f_{1}=2,000 \mathrm{~Hz}$. The frequency of the masked tone $=1,610 \mathrm{~Hz}$.

cases are different). From the ratio 1.2 to 1.3 , the decrease in masking, however, is large.

The interaction, Masker by Level, is significant in all cases with the exception of subject J.B. at the ratio 1.125 (Figure 1). By examining the Figures 1-3, one can see in most cases that the three curves, which correspond to the three maskers, diverge at a certain level of the masker depending on the case. For example, the three curves diverge when the SPL of the maskers are above 30 to $50 \mathrm{~dB}$ at the ratio 1.2 and
60 to $70 \mathrm{~dB}$ at the ratio 1.3 . For the ratio 1.125 , the divergence is obvious only for subject M.F. and occurs at the masker level of about $40 \mathrm{~dB}$ SPL.

\section{DISCUSSION}

Zwicker and Fastl (1973) compared the masking produced by the two maskers, (1) $f_{1}(2,000 \mathrm{~Hz})+f_{2}$ $(2,500 \mathrm{~Hz})$ and $(2) f_{1}+N B N, 100 \mathrm{~Hz}$ wide centered at $f_{2}$, and found that the difference in masking thresholds between the two was about $9 \mathrm{~dB}$. The latter produced a higher threshold than the former. They attributed the difference to the time structure of the masker. The artificial narrow band noise with three components created by the authors seems to have proved this point. That narrow band noise is a better masker than a pure tone masker is not new. Egan and Hake (1950) compared the masking audiograms of a pure $400-\mathrm{Hz}$ tone and a narrow band of noise $(90 \mathrm{~Hz}$ wide centered at $410 \mathrm{~Hz}$ ), both at $80 \mathrm{~dB}$ SPL. At signal frequencies near the maskers, the narrow band was a much more effective masker than the pure tone. The difference was as much as $18 \mathrm{~dB}$.

Greenwood (1971) was aware of the interaction of the tonal masker and the pure tone signal. He was able to show dips at the lower slope of the audiogram where the combination tones were located. He there-

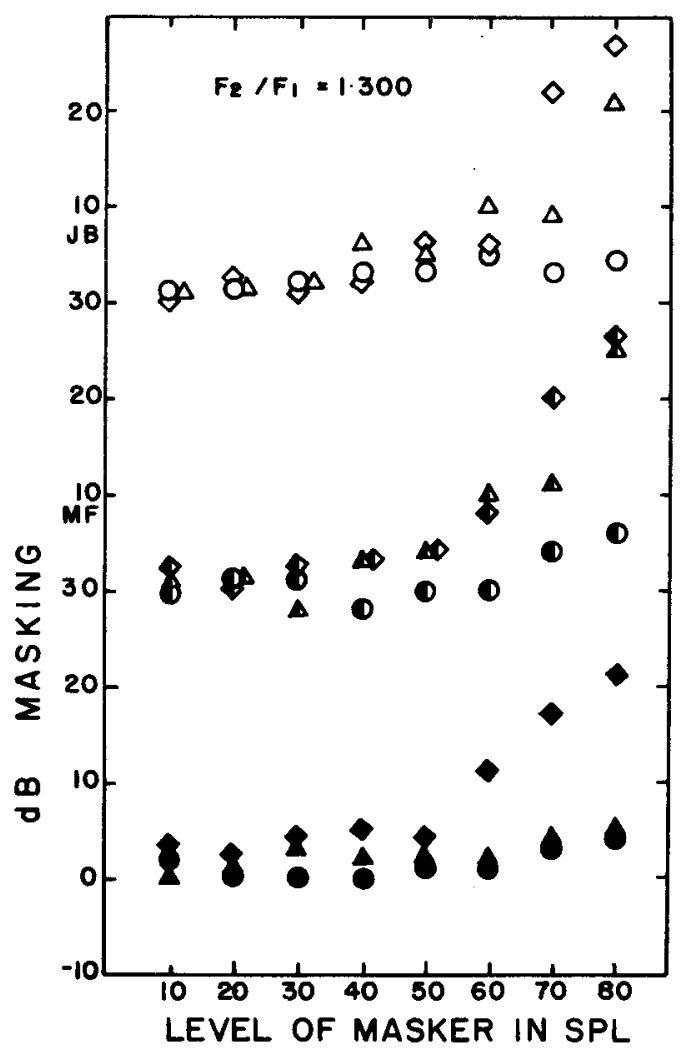

Figure 3. See caption of Figure 1, except that $f_{1}=2,000 \mathrm{~Hz}$. The frequency of the masked tone $=1,410 \mathrm{~Hz}$. 
fore used either a narrow band centered at $f_{2}$ or two narrow bands centered at both $f_{1}$ and $f_{2}$ instead. In our experiments, by using the signal frequency at $10 \mathrm{~Hz}$ above the combination tone frequency $2 f_{1}-f_{2}$, in the case of the masker being $f_{1}+f_{2}$, the threshold was more a threshold of modulation than a tonal threshold, as mentioned by a subject in Zwicker and Fastl's (1973) paper. By changing $f_{2}$ into a narrow band, this modulation was no longer prominent. However, the change from one type of masker to another did not seem to affect the criterion, detection of a difference, used by the subjects. The modulation merely made it easier to be detected.

For low ratios of $f_{2} / f_{1}$, both the two maskers, $f_{1}$ alone and $f_{1}+N B N$ are both producing about the same amount of masking. This does not disagree with Greenwood's (1972b) finding that masking produced by a noise is not increased by adding a high-intensity and higher frequency tone to the noise. The most severe condition he used was an $80-\mathrm{dB}$ SPL tone $\left(f_{1}\right)$ added to a $35-\mathrm{dB}$ narrow band of noise ( $50 \mathrm{~Hz}$ wide) centered at $\left(f_{1}-0.125 f_{1}\right) \mathrm{Hz}$. This frequency is equivalent to a cubic difference tone produced by two primaries having a ratio $f_{2} / f_{1}=$ 1.125 (Figure 2D in Greenwood, 1972b). Both in terms of the ratio and the SPL of $f_{1}$, the conditions are very similar to the conditions shown in Figure 1, when masker level is $80 \mathrm{~dB}$ SPL. This is reasonable, because the level of the combination tone is expected to be about 30 to $35 \mathrm{~dB}$ SPL (Goldstein, 1970). Since the curve in Figure 2D of Greenwood (1972b) does not indicate any shoulder, it shows that the added noise does not increase the masking.

For the ratio $\mathrm{f}_{2} / \mathrm{f}_{1}$ equal to 1.2 , the effects of masking by the three maskers deviate. $f_{1}$ alone acquires a gentler slope, while $f_{1}+$ NBN becomes the most prominent masker. $f_{1}+f_{2}$ remains the lowest of the three maskers for subjects D.C. and M.F. Here, the three curves diverge at about $30-50 \mathrm{~dB}$ SPL in masker level, depending on the subject. Assuming that the divergence is due to the correspondence of the combination tones, this level should be where the combination tone begins to occur. This implies that there are large individual differences in the level where the combination tones arise. This assumption is supported by the fact that when $f_{2} / f_{1}=1.3$, the divergence occurs at a higher level of masker, at around 60 to $70 \mathrm{~dB}$ SPL. This is expected from the fact that increasing $\mathrm{f}_{2} / \mathrm{f}_{1}$ decreases the combination tone level.

The interesting part of the results is that $f_{1}$ alone is a better masker than $f_{1}+f_{2}$ for subjects D.C. and M.F. at ratios 1.125 and 1.2. For subject J.B., however, this is not true. The reason is obscure. From the data, it seems that as the level of the masker gets higher the difference in masking between the two maskers becomes smaller. It is possible that at masked threshold measurement the difference in level between the signal and the combination tone becomes larger as the level of the masker increases, and therefore the modulation becomes weak so that the masked threshold gets higher. Does modulation release so much masking from the masker? There may be some other mechanisms involved in this. The residual masking of $f_{1}$ at the frequency of the CDT, therefore, should not be neglected for the ratio of $\mathrm{f}_{2} / \mathrm{f}_{1}<1.3$. Above this ratio, the contribution of $\mathrm{f}_{1}$ on masking becomes minimal.

Greenwood (1972b) reported that at higher primary levels the decrease in combination band level became less as $f_{2} / f_{1}$ was increased. There does not seem to have been such a trend in subjects reported here except perhaps for subject J.B. In Figure 13 of Greenwood's paper (1972a), the levels that show such effects are 85 and $95 \mathrm{~dB}$ SL. Both are higher than the levels reported here. This may be the reason why such a finding does not concur with the data here.

Smoorenburg (1972) found significant interpersonal differences in the width of the audibility region. These differences cannot be accounted for by threshold differences. There was only 1 subject out of 40 who could perceive a combination tone when the ratio $f_{2} / f_{1}$ was smaller than 1.15 and the level of each component was $40 \mathrm{~dB}$ SL. From such a finding, it is not surprising that subject J.B. deviated from the other two subjects in that he did not show a significant difference in the Masker by Level effect when the ratio $f_{2} / f_{1}=1.125$. When the ratio was higher, all subjects showed significance in the Masker by Level effect. This is consistent with the suggestion that the divergence of the masking produced by the three maskers is an indication of the presence of the combination tone. Another reason may have been due to the lack of evidence in subject J.B.

This study supports Greenwood's results in that for a masking experiment on CDT, the noise band has to be used. When masking with only two tones, $f_{1}+f_{2}$ is not a good indicator of masking. This study further shows that masking data with too low a ratio (e.g., 1.125) are not reliable because of the masking contributed by the tone $f_{1}$. In Figure 7 of Zwicker and Fastl's (1973) paper, one can see very similar results between those obtained from the method of compensation and those from masking with $f_{1}+$ NBN. The ratio they used was 1.25 , which, as shown from our data here, could be large enough for a good estimate of the CDT level. 


\section{REFERENCES}

Egan, J. P., \& Hake, H. W. On the masking pattern of a simple auditory stimulus. Journal of the Acoustical Society of America, $1950,22,622-630$.

Goldstein, J. L. Auditory nonlinearity. Journal of the Acoustical Society of America, 1967, 41, 676-689.

Goldstein, J. L. Aural combination tones. In R. Plomp \& G. F. Smoorenburg (Eds.), Symposium on frequency analysis and periodicity detection in hearing. Leiden, Holland: Sijthoff, 1970. Pp. 230-247.

Goldstein, J. L., \& KIANG, N. Y.-S. Neural correlates of the aural combination tone $2 \mathrm{f}_{1}-\mathrm{f}_{2}$. Proceedings of IEEE, 1968, 56, 981-992.

GreENwood, D. D. Aural combination tones and auditory masking. Journal of the Acoustical Society of America, 1971, 50, $502-543$.

GREeNWOOD, D. D. Masking by combination bands: Estimation of the levels of the combination bands $(n+1) f_{1}-n_{h}$. Journal of the Acoustical Society of America, 1972, 52, 1144-1154. (a)

GREENWOOD, D. D. Masking by narrow bands of noise in proxim- ity to more intense pure tones of higher frequency: Application to measurement of combination band levels and some comparisons with masking by combination noise. Journal of the Acoustical Society of America, 1972, 52, 1137-1143. (b)

SMOORENBURg, G. F. Audible region of combination tones. Journal of the Acoustical Society of America, 1972, 52, 603-614.

WEgEL, R. L., \& LANE, C. E. The auditory masking of one pure tone by another and its probable relation to the dynamics of the inner ear. Physics Review, 1924, 23, 266-285.

Wolf, R. V., \& BILGER, R. C. Generating complex waveforms. Behavior Research Methods \& Instrumentation, 1972, 4, 250-256.

ZWICKER, E. Der ungewöhnliche Amplitudengang der nichtlinearen Verzerungen des Ohres. Acustica, 1955, 5, 67-74.

ZWICKER, E., \& FAsTL, H. Cubic difference sounds measured by threshold- and compensation- method. Acoustica, 1973, 29, 336-343.

(Received for publication November 8, 1976; revision accepted May 26, 1977.) 